Keywords: Mental disorders; Epidemiological community study; Outcome; Long-term course; Externalizing Behaviour; Conduct Disorders.

\title{
Acting out and self-harm in children, adolescents and young adults and mental illness 18 years later: The Longitudinal Upper Bavarian Community Study
}

\author{
Gabriele Kohlboeck, PhD, \\ Norbert Quadflieg* \\ Manfred M. Fichter, MD ${ }^{\star, \star \star \star}$
}

* Department of Psychiatry, University of Munich

** Helmholtz Zentrum München, German Research Center for Environmental Health

*** Schön Klinik Roseneck

GERMANY

ABSTRACT - Background and Objectives: To assess the predictive impact of childhood/adolescent/young adult acting out and self-harm in a community sample of 224 participants on mental illness 18 years later.

Methods: Assessments focusseded on a baseline in 1980-84 and the results at a 18-year follow-up from 2001-2004. Self-rating scales as well as expert-rating interviews yielded data on acting out, self-harm, psychiatric diagnoses and psycho-social outcome.

Results: The participation rate at 18-year follow-up was $82 \%$ of those of the baseline sample. Regression analyses showed these results: Acting out and self-harm predicted later mood disorders. Self-harm predicted later psychiatric treatment in the year preceding 18-year follow-up, and impairment in social functioning.

Conclusions: Our data contribute to a better and broader understanding of the impact of acting out and self-harm in childhood/adolescence/young adulthood on mental illness and its consequences in adult age and underscore the need for early and intensive intervention at many levels to prevent the accumulation of psychological problems in this age.

Received: 8 December 2009

Revised: 13 October 2010

Accepted: 19 October 2010 


\section{Introduction}

Externalizing behaviour problems refer to a grouping of behaviour problems that are manifested in children's outward behaviour and reflect the child negatively acting on the external environment ${ }^{1,2}$. Whereas internalizing behaviours are evidenced by withdrawal, dysphoria and anxiety, externalizing behaviours are marked by defiance, impulsivity, hyperactivity, aggression and antisocial features.

Robins' ${ }^{3}$ follow-up of antisocial boys, together with an appropriately matched general population control group, showed that in adult life antisocial boys had a greatly increased rate of a whole range of negative life experiences including unemployment, broken marriages, rebuffs from friends, and lack of social support. These findings have been replicated by Champion, Goodall, and Rutter $^{4}$ who showed that London schoolchildren with conduct problems at age 10 had a much increased rate of negative life events carrying psychological threat some 18 years later. Similarly, Fergusson, Horwood and Ridder ${ }^{5}$ reported that conduct problems at age 7 to 9 years were associated with increased risks of substance use, mood and anxiety disorders and suicidal acts in early adulthood (aged 21 to 25 years). Concerning prediction of adult psychopathology, one study found links of parent-reported externalizing behaviour to social functioning in adulthood ${ }^{6}$. Covering the age from 13 to 53 years, Colman et al. ${ }^{7}$ found that adolescents with mild or severe externalizing behaviour showed negative outcome on a composite measure of global adversity throughout adulthood.

To our knowledge no research, has investigated how severe acting out behaviour (e.g. lying, stealing or running away) and selfharm are linked to mental illness in midadulthood. Self-harm is not described as an externalizing behaviour in the research literature, but deliberate self-harm in children or adolescents is associated with externalizing behaviour in the general population ${ }^{8-10}$.

\section{Methods}

\section{Sample}

In the 1970 s a representative random sample of 396 children and adolescents aged 3 to 15 years was drawn from the registration offices in South Eastern Upper Bavaria ${ }^{11}$. Of the originally drawn sample of 396, fiftyone $(12.9 \%)$ refused participation or could not be reached for assessment and 345 participated in the 1980 s survey ( 5 to 8 years after the sample was drawn) which for this paper is the baseline assessment. For the follow-up interviews between 2000 and 2004 we were able to reach $283(82 \%)$ of the 345 participants (aged 9 to 22 years) of the baseline sample from the 1980s. Refusals at follow-up were low at $9.9 \%(\mathrm{~N}=$ 34). Twenty-six $(7.5 \%)$ persons could not be traced or contacted, and two individuals were deceased in the time interval between the two assessments. Analyses of baseline interview data in the 1980s showed no significant differences between participants and non-participants at follow-up interviews in the 2000s. Complete data for the present analyses were available for 224 participants (117 male (52.2\%), 107 female (47.8\%)) who constituted the sample for which data are presented in this paper.

\section{Assessments}

\section{Baseline}

Acting out behaviours and self-harm were assessed by the structured "Mannheimer Interview", which in the first part of the 1980s 
was an acceptable instrument for research in developmental abnormalities ${ }^{12}$. At the end of each section of this interview covering a specific acting out behaviour the interviewer assessed the severity of the problem for the last seven days and the last 5 years preceding the interview as reported by the proband, scored $0=$ no symptoms, $1=$ symptom present, and $2=$ very pronounced symptoms present.

A comprehensive measure of 'Acting Out' (ranging from 0 to 12) was created by summing up the severity ratings of relevant behaviours as follows:

- Breaches of discipline at school were present (1) if there were several punishments or if the proband had been called to the headmaster in the last 6 months, and very pronounced (2) if disciplinary problems were out of control and the proband was confronted with getting dismissed from school.

- Skipping classes was present (1) if proband skipped classes for more than four hours or 1 day in the last 6 months, and very pronounced (2) if subject skipped classes for more than 20 hours or more than 4 days in the last 6 months.

- Lying was present (2) if lying was a problem for the family or proband lied at least 3 times a months in the last 6 months; (2) very pronounced if the proband was lying on a daily basis or several times a week, which caused significant problems in his/her family.

- Stealing was present (1) if something valuable in the last 6 months had been stolen or less valuable objects had been stolen more than 4 times in the last 6 months; (2) very pronounced if something valuable was stolen on several occasions in the last 6 months.
- Destroying was present (1) if the proband caused significant damage in the last 6 months; (2) very pronounced if the proband did significant damage more than once in the last 6 months.

- Running away was present (1) if proband had been running away from his/her family in the last 6 months; (2) very pronounced if the proband was running away several times in the last 6 months.

Self-harm was rated as present if the proband reported at least one of the following: beating the head against the wall, cutting, pulling out hair, stubbing out cigarettes on his/her skin.

The Standardized Psychiatric Interview $\left(\mathrm{SPI} ;{ }^{13}\right)$ and psychiatric diagnoses were assessed by the clinical investigators.

\section{Eighteen-year outcome}

The Composite International Diagnostic Interview (CIDI; ${ }^{14,15}$ ) yielded assessments of mental disorders during the 12 months preceding the interview. Based on information obtained from the CIDI and clinical judgement, psychiatric diagnoses were given on the basis of the $10^{\text {th }}$ revision of the ICD. Participants were asked about the use of inpatient and outpatient psychiatric or psychotherapeutic treatment in the last 12 months before the follow-up interview. The overall functioning of the participant at the time of the interview was rated using the Global Assessment of Functioning (GAF) from to the DSM-IV. The scale values range from 1 to 100 with higher scores indicating good functioning, while lower scores indicate different levels of impairment. Individuals were assigned to have at least mild impairment $[0=$ no, $1=$ yes $]$ in global functioning if a code of 70 or less (mild symptoms) was assessed for the week preceding the interview. 
Interviews were conducted by psychiatric residents (baseline) and by trained clinical psychologists (follow up). The study was approved by the ethics committee of the University of Munich. Written informed consent was given by participants prior to the interview.

\section{Statistical analysis}

$\mathrm{Chi}^{2}$-tests were used for comparing frequencies of variables. Analyses of variance with post-hoc Scheffé-tests were computed to compare means in gender and three different age groups at baseline. We performed forward stepwise logistic regression analyses to identify predictors for any psychiatric disorders and specific categories of adult psychiatric disorders $(0=$ no disorder, $1=$ disorder), psychiatric/psychotherapeutic treatment last year $(0=$ no, $1=$ yes $)$, and for at least mild impairment of functioning $(0=$ no, 1 = yes) at follow-up.

The comprehensive measure "acting out", as well as self-harm of the Mannheim Interview were tested as single predictors in separate stepwise logistic regressions for each outcome criterion. Both predictors were included in the final predictive models including covariates gender and age and odds ratios were estimated.

\section{Results}

Subjects were reassessed $17.9 \pm 0.8$ years after the baseline survey. Mean age at follow-up was $33.8 \pm 3.4$ years (range 26 to 40 years). The 60 probands who refused to participate or could not be located at 18-year follow-up did not differ from study participants regarding age, sex, education, psychi- atric treatment, or number of psychiatric diagnoses at baseline. Individuals who did not take part in the 18-year follow-up had significantly higher SPI psychopathology overall scores $(\mathrm{F}=5.59$, df $=1, \mathrm{p}=0.019)$ and were more likely to be diagnosed with social phobia $\left(\mathrm{chi}^{2}=4.40, \mathrm{df}=1, \mathrm{p}=0.037\right)$ and adjustment reactions $\left(\mathrm{chi}^{2}=6.22, \mathrm{df}=\right.$ $1, p=0.013$ ) at baseline than participants.

Baseline data on the final sample and the frequency of acting-out and self-harm is shown in table 1. Males and females did not differ significantly in any of the variables. About one quarter of the sample was identified as showing acting out including mild or minor symptoms.

Older subjects aged 15-22 showed more acting out at baseline $(\mathrm{M}=1.16+/-2.01$ $\mathrm{SD})$ than subjects aged $9-11$ years $(\mathrm{M}=$ $0.28+/-0.96 \mathrm{SD})(\mathrm{F}=35.74, \mathrm{p}<0.01, \mathrm{df}=2$; Scheffé $\mathrm{p}<0.05)$.

Table 2 gives the prevalence of mental disorders at follow-up.

About one quarter of the subjects had at least one psychiatric disorder at follow-up. Anxiety disorders were found most frequently with a higher rate in females. Only males were identified with substance use disorders.

As single predictors neither acting out nor self-harm predicted the presence of any mental disorder, anxiety disorder, or substance use disorder 18 years later. Both acting out and self-harm predicted mood disorder at follow-up (Table 3). In the final model including co-variates, gender was also a significant predictor of mood disorder but not age at baseline (Table 4).

Use of inpatient or outpatient psychiatric or psychotherapeutic treatment services in the 12 months preceding the follow-up interview was reported by $3.6 \%$ of the sample ( $\mathrm{N}=5 ; 1$ man, 4 women). Self-harm at ba- 
Table 1

Baseline Characteristics in Children, Adolescents and Young Adults ( $\mathrm{N}=224)$

\begin{tabular}{|c|c|c|c|c|c|}
\hline & \multicolumn{2}{|c|}{ Males (n = 117) } & \multicolumn{2}{|c|}{ Females $(\mathrm{n}=107)$} & \multirow[t]{2}{*}{ chi $^{2}$-tes } \\
\hline & $\mathrm{n}$ & $\%$ & $\mathrm{n}$ & $\%$ & \\
\hline Age group at baseline & & & & & $\mathrm{ns}$ \\
\hline $9-11$ yrs & 9 & 7.7 & 13 & 12.1 & $\mathrm{df}=2$ \\
\hline $12-14$ yrs & 32 & 27.4 & 20 & 18.7 & \\
\hline $15-22 \mathrm{yrs}$ & 76 & 65.0 & 74 & 69.2 & \\
\hline Social Class of Parents & & & & & ns \\
\hline $1=$ Upper Class & 10 & 8.7 & 6 & 5.7 & $\mathrm{df}=4$ \\
\hline $2=$ Middle Class & 6 & 5.2 & 16 & 15.1 & \\
\hline $3=$ Lower Middle Class & 38 & 33.0 & 31 & 29.2 & \\
\hline $4=$ Upper Working Class & 43 & 37.4 & 44 & 41.5 & \\
\hline $5=$ Lower Working Class & 18 & 15.7 & 9 & 8.5 & \\
\hline $\begin{array}{l}\text { 'Acting Out'- (breaches of disc } \\
\text { classes, lying, stealing, destroy } \\
\text { running away) }(\mathrm{n}=224)\end{array}$ & & & & & ns \\
\hline $0=$ no & 90 & 76.9 & 77 & 72.0 & $\mathrm{df}=1$ \\
\hline $1=$ yes & 27 & 23.1 & 30 & 28.0 & \\
\hline Self-harm $(n=224)$ & & & & & ns \\
\hline $0=$ none & 114 & 97.4 & 106 & 99.1 & $\mathrm{df}=1$ \\
\hline 1 symptom & 1 & 0.9 & 0 & 0 & \\
\hline 2 symptoms & 2 & 1.7 & 0 & 0 & \\
\hline 3 symptoms & 0 & 0 & 1 & 0.9 & \\
\hline
\end{tabular}

note: $\mathrm{ns}=$ not significant.

Table 2

Prevalence of Adult ICD-10 Psychiatric Disorders at 18-year Follow-up

\begin{tabular}{lccc} 
& Males $(\mathrm{N}=117)$ & Females $(\mathrm{N}=107)$ & Total $(\mathrm{N}=224)$ \\
$\mathrm{N}(\%)$ & $\mathrm{N}(\%)$ & $13(\%)$ \\
\hline Mood Disorders $^{1}$ & $2(1.7)$ & $11(10.3)$ & $33(14.7)$ \\
\hline Anxiety Disorders & $13(11.1)$ & $20(18.7)$ & $8(3.6)$ \\
\hline Substance Use Disorders & $8(6.8)$ & 0 & $58(25.9)$ \\
\hline Any (at least 1) Disorder & $27(23.1)$ & $31(29.0)$ & \\
\hline
\end{tabular}

${ }^{1}$ Only unipolar depression was found. 
Table 3

Acting Out and Self-harm in Childhood/Adolescence/Young Adulthood (Baseline) as Single Predictors for Adult Mental Illness

\begin{tabular}{|c|c|c|c|c|c|c|c|c|c|}
\hline \multirow[b]{2}{*}{ Predictors: } & \multicolumn{3}{|c|}{$\begin{array}{c}\text { Any } m o o d \text { disorder last } \\
\text { year follow-up } \\
(0: \text { no } n=211,1: \text { yes } n=13)\end{array}$} & \multicolumn{3}{|c|}{$\begin{array}{l}\text { Any psychiatric treatment } \\
\text { last year follow-up } \\
(0: \text { no } n=199,1 \text { : yes } n=5)\end{array}$} & \multicolumn{3}{|c|}{$\begin{array}{c}\text { Impairment in global } \\
\text { functioning } \\
(0: \mathrm{no} \mathrm{n}=206,1: \text { yes } \mathrm{n}=14)\end{array}$} \\
\hline & $\mathrm{R}^{2 \mathrm{a}}$ & $\mathrm{OR}^{2 \mathrm{~b}}$ & ${ }_{95 \%} \mathrm{CI}$ & $\mathrm{R}^{2}$ & OR & ${ }_{95 \%} \mathrm{CI}$ & $\mathrm{R}^{2}$ & OR & ${ }_{95 \%} \mathrm{CI}$ \\
\hline Acting out & 0.11 & 1.40 & $1.14-1.72$ & - & - & - & - & - & - \\
\hline Self-harm & 0.04 & 2.79 & $1.02-7.63$ & 0.13 & 4.37 & $1.47-13.1$ & 0.04 & 2.67 & $0.98-7.26$ \\
\hline
\end{tabular}

Table 4

Final Model: Acting Out and Self-harm in Childhood/Adolescence/Young Adulthood (Baseline) as Predictor for Adult Mental Illness ( $\mathrm{N}=224$ )
Any mood disorder last year follow-up$$
\mathrm{R}^{2}=0.22
$$
Any psychiatric treatment last year follow-up $\mathrm{R}^{2}=0.13$
Impairment in global functioning $\mathrm{R}^{2}=0.18$

\begin{tabular}{lccccccccc}
\hline Predictors: & Wald & OR & ${ }_{95 \%} \mathrm{CI}$ & Wald & OR & ${ }_{95 \%} \mathrm{CI}$ & Wald & OR & ${ }_{95 \%} \mathrm{CI}$ \\
\hline Self-harm & 3.64 & 3.7 & $0.97-13.80$ & 6.99 & 4.4 & $1.47-13.05$ & 3.68 & 2.67 & $0.98-7.26$ \\
\hline Acting out & 8.63 & 1.4 & $1.11-1.71$ & & & & & & \\
\hline Gender & 5.42 & 6.4 & $1.34-30.12$ & & & & & &
\end{tabular}

$\mathrm{OR}=$ Odds Ratio $; \mathrm{CI}=$ Confidence Interval.

seline was a significant single predictor (Table 3) for psychiatric or psychotherapeutic treatment in the 12 months preceding follow-up. In the final regression model controlling for age and gender, self-harm explained $13 \%$ of the variance (Table 4 ).

Impairment in functioning (GAF) at follow-up (mild or more severe) was found in $6.4 \%$ of the sample $(\mathrm{N}=14$ [50\% men, 50\% women]). This outcome was predicted by self-harm as single predictor (Table 3), and also in the final model controlling for age and gender.

\section{Discussion}

The strengths of our study are its prospective longitudinal design and its long follow-up period. Our participation rate of $82 \%$ of the baseline sample $(71 \%$ of the original sample) is relatively high considering the long follow-up interval ${ }^{16}$.

Limitations: (1) Due to the long interval of 18 years relevant information on psychiatric symptoms beginning and ending within the follow-up interval might have been 
concealed from us leading to an under-estimation of actual mental illness in adulthood. Another source of possible under-reporting is that due to budget restrictions we had to rely solely on the information provided by the participants. (2) The heterogeneous age range may have confused results for prediction of psychiatric disorders as subjects older 14 years at baseline showed more acting out than younger subjects. Thus younger subjects had a lower probability for conduct problems than older subjects which may have affected our results. We accounted for this possibility by controlling age in the final analyses. (3) In analyzing acting out and self-harm, we did not consider the influence of negative social circumstances. Socio-economic position and circumstances may affect adjustment in childhood and adolescence resulting in impaired adult psychosocial functioning ${ }^{17}$.

We focusseded on acting out and self-harm as predictors for adult psychopathology. Acting-out behaviour is one of the characteristics clustered under the broader grouping of conduct disorders, but not necessarily as severe $^{18}$. Since our sample size was too low to permit meaningful statistical analyses of conduct disorders, the focus on a comprehensive measure acting out behaviours, allowed us to examine their impact on adult psychopathology. Self-harm behaviour -without suicidal intent- is known as a serious health problem ${ }^{19}$ and some reports characterize aggressive acts against one's own body as indicative of especially severe psychopathological problems ${ }^{20,21}$.

\section{Mental illness}

We could demonstrate that acting out and self-harm were related to adult depression. No association between early acting out and other psychiatric disorders at follow-up was found.
Other studies provided partial confirmation of our findings concerning diagnostic outcome. In a large sample of children from Zuid-Holland aged about 11 to 18 years at baseline assessment high scorers of self-reported childhood problems showed higher rates of any DSM-IV diagnosis and of mood disorders ten years later ${ }^{22}$. The Dunedin study gave evidence for all mental disorders (any, anxiety, depressive and substance use disorder) at age 26 having a disorder specific precursor diagnosis in 50 to $55 \%$ at age 11 to 15 , and in 22 to $24 \%$ at age $18^{26}$. Adult age in both these studies was younger than in our sample. A German study reported similar results as in the Zuid-Holland study ${ }^{23}$.

Although in our study the prevalence of mood disorders in males at follow-up was lower than in females, mood disorders were associated with a composite measure of mild and severe externalizing behaviour ("acting out"). Investigating 40-year outcome of conduct disorders, Colman et al. ${ }^{7}$ found that symptoms of depression were more common among those with mild and severe externalizing behaviour in adolescence than in those without this behaviour.

Acting out was not related to later substance use disorders in our study. This finding is not consistent with results of a number of investigations ${ }^{24-26}$. Flory et al. ${ }^{26}$ examined relations among conduct disorder and substance use and abuse and found that children with conduct problems were most at risk for the most severe forms of substance use in young adulthood.

Some differences in results from other studies may have arisen from methodological features, such as differences in assessment procedures or weak statistical power due to our smaller heterogeneous sample. Externalizing problems at a young age are quite rare and as a result, it is possible that 
the failure of our measures of acting out to predict psychiatric disorders is due to the broad age range of our sample. The inconsistency in findings may also be explained by the measures' more general failure to reliably assess all kinds of externalizing problems, e.g. aggressive behaviour.

\section{Psychosocial functioning}

In our study children/adolescents/young adults with "self-harm" were more likely to suffer from poor general functioning in adulthood.

This agrees with other studies which found an increased risk of leaving school with no qualification and social impairment as adults in individuals with childhood conduct problems even after controlling for family $\mathrm{SES}^{6,25,27}$.

\section{Conclusions}

Our data contribute to a better and broader understanding of the impact of acting out and self-harm on mental illness and its consequences in mid-adulthood and underscore the need for early and intensive intervention at many levels to prevent the accumulation of psychological, socioeconomic, and functioning problems in childhood, adolescence, and young adulthood.

\section{Acknowledgement}

We especially thank Dipl.-Psych. Eva Bolz, Dr. Marian Cebulla, Dipl.-Psych. Helen Castellanos, Dipl.-Psych. Andrea Dusold, Dipl.-Psych. Andreas Hampel, Dr.
Thomas Niedermeier, Dipl.-Psych. Birgit Schaider, Dipl.-Psych. Nicole Sevignani and Dipl.-Psych. Nadia Sosnowsky for their sensitive way of conducting interviews with the probands.

\section{References}

1. Campbell SB, Shaw DS, Gilliom M. Early externalizing behaviour problems: Toddlers and preschoolers at risk for later maladjustment. Dev Psychopathol 2000; 12:467-488.

2. Eisenberg N, Cumberland A, Spinrad TL, Fabes RA, Shepard SA, Reiser M, et al. The relations of regulation and emotionality to children's externalizing and internalizing problem behaviour. Child Dev 2001; 72: 1112-1134.

3. Robins LN. Deviant children grown up. Baltimore: Williams \& Wilkins; 1966.

4. Champion LA, Goodall G, Rutter M. Behaviour problems in childhood and stressors in early adult life. Psychol Med 1985; 25(2): 231-246.

5. Fergusson DM, Horwood LJ, Ridder EM. Show me the child at seven: the consequences of conduct problems in childhood for psychosocial functioning in adulthood. J Child Psychol Psychiatry 2005; 46(8): 837-849.

6. Bongers IL, Koot HM, Van der Ende J, Verhulst FC. Predicting young adult social functioning from developmental trajectories of externalizing behaviour. Psychol Med 2008; 38: 989-999.

7. Colman I, Murray J, Abbott RA, Maughan B, Kuh D, Croudace TJ, et al. Outcomes of conduct problems in adolescence: 40-year follow-up of national cohort. Br Med J 2009; 337: a2981.

8. Shin YM, Chung YK, Lim KY, Lee YM Oh. Childhood Predictors of Deliberate Self-Harm Behavior and Suicide Ideation in Korean Adolescents: A Prospective Population-Based Follow-Up Study. J Korean Med Sci 2009, 24: 215-222.

9. Resch F, Parzer P, Brunner R. Self-mutilation and suicidal behaviour in children and adolescents: Prevalence and psychosocial correlates: Results of the BELLA study. Eur Child Adolesc Psychiatry 2008; 17(Suppl 1): 92-98.

10. Sourander A, Aromaa M, Pihlakoski L, Haavisto A, Rautava P, Helenius $\mathrm{H}$, et al. Early predictors of deliberate self-harm among adolescents. A prospective follow-up study from age 3 to age 15. J Affect Disord 2006; 93: 87-96. 
11. Fichter MM, Kohlboeck G, Quadflieg N, Wyschkon A, Esser G. From Childhood to Adult Age: 18-year Longitudinal Results and Prediction of the Course of Mental Disorders in the Community. Soc Psychiatry Psychiatr Epidemiol 2009; 44: 792-803.

12. Esser G, Schmidt MH. Prognose und Verlauf kinderpsychiatrischer Störungen im Längsschnitt von acht bis dreizehn Jahren. In: Schmidt MH, Drömann S, eds. Langzeitverlauf Kinder. Stuttgart: Enke Verlag; 1986.

13. Goldberg DP, Cooper P, Eastwood RR, Kedward MB, Shepherd M. A standardized psychiatric interview for use in community surveys. Br J Prev Soc Med 1970; 24: 18-23.

14. Robins LN, Wing J, Wittchen HU, Helzer JE, Babor TF, Burke J, et al. The Composite International Diagnostic Interview: An epidemiologic instrument suitable for use in conjunction with different diagnostic systems and in different cultures. Arch Gen Psychiatry 1989; 45: 1069-1077.

15. Wittchen HU, Pfister H. Manual und Durchführungsbeschreibung des DIA-X-M-CIDI. Frankfurt: Swets, Zeitlinger; 1997.

16. Rothman KJ, Greenland S. Modern epidemiology. 2nd edition. Philadelphia: Lippincott-Raven; 1998.

17. Schoon I, Sacker A, Bartley M. Socio-economic adversity and psychosocial adjustment: a developmentalcontextual perspective. Soc Sci Med 2003; 57(6): 10011015.

18. Reynolds, Fletcher-Janzen. Encyclopedia of Special Education: A Reference for the Education of Children, Adolescents, and Adults With Disabilities and Other Exceptional Individuals, Volume 1. New York: John Wiley and Sons; 2007.

19. Fliege H, Lee JR, Grimm A, Klapp BF. Risk factors and correlates of deliberate self-harm behavior: a systematic review. J Psychosom Res 2009;66(6):477-493.

20. Feldman MD. The challenge of self-mutilation: a review. Compr Psychiatry 1988; 3: 252-269.
21. Herpertz S. Self injurious behaviour. Acta Psychiatr Scand 1995; 91: 57-68.

22. Hofstra MB, Van der Ende J, Verhulst FC. Adolescents' self-reported problems as predictors of psychopathology in adulthood: 10-year follow-up study. Br J Psychiatry 2001; 197: 203-209.

23. Esser G, Ihle W, Schmidt MH, Blanz B. Der Verlauf psychischer Störungen vom Kindes-zum Erwachsenenalter. Z Klin Psychol Psychother 2000; 29: 276-283.

24. Robins LN, Price RK. Adult disorders predicted by childhood conduct problems. Results from the NIMH epidemiologic catchment area project. Psychiatry 1991; 54: 116-132.

25. Fergusson DM, Horwood LJ. Early conduct problems and later life opportunities. J Child Psychol Psychiatry 1998; 39(8): 1097-1108.

26. Flory K, Milich R, Lynam DR, Leukefeld C, Clayton R. Relation between childhood disruptive behaviour disorders and substance use and dependence symptoms in young adulthood: individuals with symptoms of attention-deficit/hyperactivity disorder and conduct disorder are uniquely at risk. Psychol Addict Behav 2003; 17(2): 151-158.

27. Quinton D, Rutter M. Parental breakdown: The making and breaking of intergenerational links. Aldershot, UK: Avebury; 1988.

Address for correspondence:

Manfred M. Fichter, M.D.

Professor of Psychiatry

Schön Klinik Roseneck affiliated with

the University of Munich

Am Roseneck, 6.

83209 Prien, Germany

Tel. +49 (8051) 683510

Fax +49 (8051) 683532

E-mail: MFichter@Schoen-Kliniken.de 